\title{
Supercritical Assisted Atomization: Polyvinylpyrrolidone as Carrier for Drugs with Poor Solubility in Water
}

\author{
Sara Liparoti, Renata Adami, Giuseppe Caputo, and Ernesto Reverchon \\ Department of Industrial Engineering, University of Salerno, Via Giovanni Paolo II, 132, 84084 Fisciano, Italy \\ Correspondence should be addressed to Renata Adami; radami@unisa.it
}

Received 19 February 2013; Revised 9 May 2013; Accepted 17 May 2013

Academic Editor: Marleny D. A. Saldaña

Copyright (C) 2013 Sara Liparoti et al. This is an open access article distributed under the Creative Commons Attribution License, which permits unrestricted use, distribution, and reproduction in any medium, provided the original work is properly cited.

\begin{abstract}
Supercritical assisted atomization (SAA) is an efficient technique to produce microparticles and composite microspheres formed by polymers and pharmaceutical compounds. In this work polyvinylpyrrolidone (PVP) was proposed as carrier for pharmaceutical compounds that show a poor solubility in water medium. Indeed, this polymer is hydrosoluble and can be generally used to enhance the dissolution rate of hydrophobic compounds when finely dispersed in it. However, it is difficult to obtain coprecipitates with a uniform dispersion of the active molecule using other micronization techniques. The experiments were performed using ethanol as solvent; SAA plant was operated at $40^{\circ} \mathrm{C}$ and 76 bar in the saturator and $70^{\circ} \mathrm{C}$ and 1.6 bar in the precipitator. Three different dexamethasone/polymer weight ratios were selected: $1 / 2,1 / 4$, and $1 / 8$. Produced composite particles showed a regular, spherical shape and a mean diameter ranging from about 0.8 to $1 \mu \mathrm{m}$, depending on the polymer/drug weight ratio. Dissolution analysis demonstrated that microparticles containing a lower drug amount show a higher dissolution rate.
\end{abstract}

\section{Introduction}

Poor water solubility of several drugs largely limits their bioavailability. To improve the dissolution rate of drugs, different strategies have been developed; the most common approach is based on particle size reduction, but a good method is also the dispersion of the hydrophobic molecule into a hydrophilic polymeric matrix. Polyvinylpyrrolidone (PVP) is one of the most used carrier to enhance the dissolution rate of hydrophobic compounds [1] because it is soluble in water and in other organic solvents and is nontoxic. PVP is also used to suppress recrystallization [2] of active molecules, as coating agent for iron oxide nanoparticles, to produce MRI contrast agents [3]. Moreover, it was found that PVP increases the activity of some active molecules, such as anticancer drugs [4].

The most used techniques to produce solid dispersions are solvent evaporation [5], spray drying [6], and freeze drying [7]. Solvent evaporation involves the use of organic solvents that contaminate the final product [8]. Spray drying allows obtaining regular-shaped particles, but temperatures used for this process are problematic for thermolabile compounds [9]. Spray freeze drying involves the use of very low temperatures that could modify the structure of the processed compounds [10].

To overcome the limits of the traditional techniques some supercritical fluid assisted techniques have been proposed $[11,12]$. More specifically some authors attempted to produce PVP coprecipitates; Wu et al. [6] proposed the coprecipitates of PVP and piroxicam using methylene chloride, obtaining spherical particles for coprecipitates and needle-like crystal when piroxicam alone was processed. Kluge et al. [13] proposed the same technique to produce $\mathrm{PVP} /$ phenytoin coprecipitates, obtaining particles with a mean diameter ranging between 200 and $500 \mathrm{~nm}$. Also in this case the pure drug (phenytoin) when processed by SAS produced large crystals. Generally speaking these results are in favor of the capacity of PVP to inhibit crystallization of guest molecules $[14,15]$.

Supercritical assisted atomization (SAA) is an efficient technique that has been used to produce microparticles and coprecipitates of several kinds of compounds: active molecules, proteins, and polymers [16-20]. Indeed, during SAA process, droplets formation takes place. These droplets contain both compounds and, usually, selecting proper carrier/drug weigh ratios; it is possible to obtain polymeric 


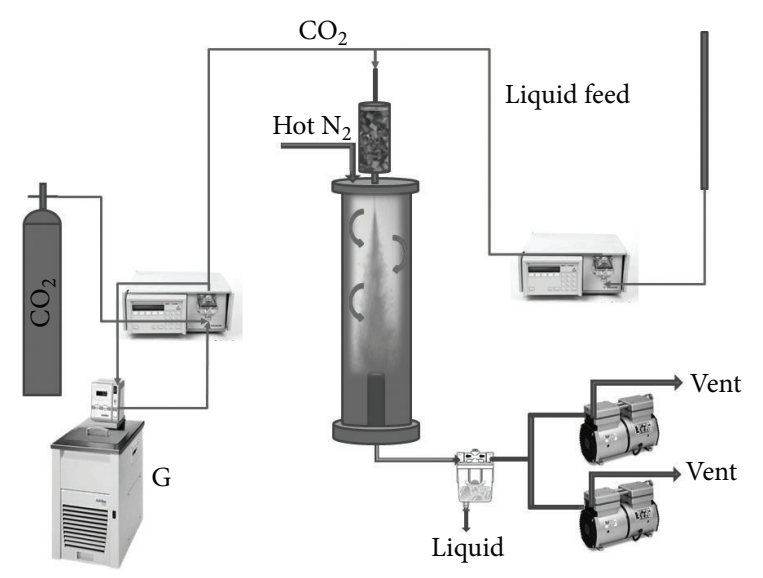

FIGURE 1: Scheme of SAA plant. G is the cool bath to cold the head of high pressure pump.

matrix in which the active compound is uniformly dispersed [21].

For all these reasons, the aim of this work is to produce composite microparticles of PVP and dexamethasone, selected as model drug with poor solubility in water, using SAA process. Different drug-polymer ratios were selected, $1 / 2,1 / 4$, and $1 / 8$, morphological analysis was performed on coprecipitates and dissolution rate analysis was performed on the composite microparticles.

\section{Materials and Methods}

$\mathrm{CO}_{2}$ (99.9\%, SON, Naples, Italy), nitrogen $\left(\left(\mathrm{N}_{2}\right) 99.9 \%\right.$, SOL, Milan, Italy), acetone (99.5\%, Panreac, Barcelona, Spain), ethanol (99.5\%, Aldrich Chemical Co., Milan, Italy), polyvinylpyrrolidone ((PVP) Mw: 10000, Aldrich Chemical Co., Milan, Italy), and dexamethasone (purity 99.8\%, ICN Biomedicals, Milano, Italy) were used as received.

The configuration of SAA plant consists of two high-pressure pumps delivering the liquid solution and liquid $\mathrm{CO}_{2}$ to the saturator. The saturator is a high pressure vessel (internal volume $50 \mathrm{~cm}^{3}$ ) loaded with stainless steel perforated saddles which assure a large contact surface between liquid solution and $\mathrm{CO}_{2}$. The solution obtained in the saturator is sprayed through a thin wall $(80 \mu \mathrm{m}$ diameter) injection nozzle into the precipitator (IV $3 \mathrm{dm}^{3}$ ). A controlled flow of $\mathrm{N}_{2}$ was sent to the precipitator to assist liquid droplets evaporation. A stainless steel filter, located at the bottom of the precipitator, allows the powder collection and the gaseous stream flow out. Downstream the precipitator, a condenser separates the liquid stream from the inert gas. SAA apparatus layout was reported elsewhere [19]. A scheme of SAA plant is reported in Figure 1.

The morphology of PVP particles was observed by a field emission-scanning electron microscope ((FESEM) mod. LEO 1525, Carl Zeiss SMT AG, Oberkochen, Germany).

Particle size (PS) and particle size distribution (PSD) were measured by SEM photomicrographs using the Sigma Scan Pro Software (release 5.0, Aspire Software International, Ashburn, VA, USA). Approximately 1000 particles were

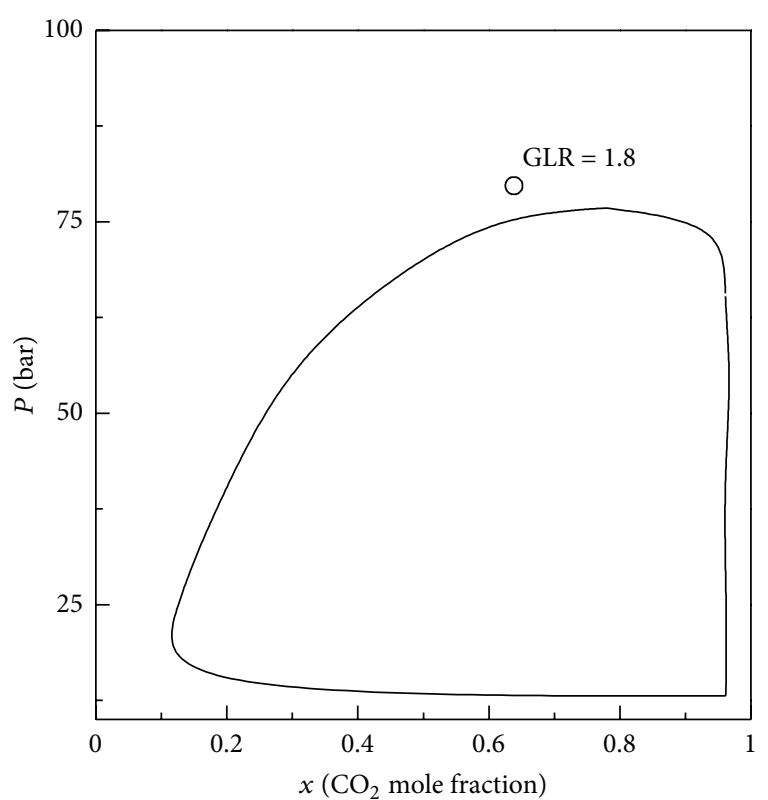

FIGURE 2: Vapor liquid equilibria for the system ethanol- $\mathrm{CO}_{2}$ at $40^{\circ} \mathrm{C}$. Adapted from Knez et al. [22].

measured for each particle size distribution calculation. Histograms, representing the particle size distribution, were fitted using Microcal Origin Software (release 8.0, Microcal Software, Inc., Northampton, MA, USA).

Solid state analysis of the precipitates was performed using an X-ray powder diffractometer ((XRPD) model D8 Advance; Bruker AXS, Madison, WI, USA) with a $\mathrm{Cu}$-sealed tube source. The measuring conditions were $\mathrm{Ni}$-filtered $\mathrm{Cu}$ Ka radiation, $11 / 41.54 \mathrm{~A}$, and $2 \Theta$ angle ranging from 2 to 50 with a scan rate of $1 \mathrm{~s} / \mathrm{step}$ and a step size of 0.05 .

Drug content in SAA composite microparticles was determined to verify if the ratio between polymer and drug, set in the liquid solution, is maintained. A known amount of dexamethasone-loaded microparticles was suspended into a physiological saline solution at $\mathrm{pH}$ 7.2. The suspension was kept at $37^{\circ} \mathrm{C}$ and stirred at $200 \mathrm{rpm}$ for 5 days. The amount of drug incorporated was assayed by spectrophotometric analysis, using UV-vis (Cary 50 Scan, Varian) at $242 \mathrm{~nm}$. Drug release profiles over the time were obtained using a physiological saline solution ( $\mathrm{pH}$ 7.2) as the dissolution medium. These studies were performed in triplicate for each sample.

\section{Results}

The key factor of SAA processing is the solubilisation of supercritical $\mathrm{CO}_{2}$ in the solution containing the compound to be micronized [23]. Indeed the solubilisation of supercritical $\mathrm{CO}_{2}$ in the liquid feed allows reducing viscosity and surface tension of the system, enhancing the atomization process. The effective amount of $\mathrm{CO}_{2}$ that can solubilise in the liquid feed is correlated to the vapor liquid equilibria (VLE) solvent- $\mathrm{CO}_{2}$. In this work, ethanol was selected for SAA micronization experiments since PVP and dexamethasone 


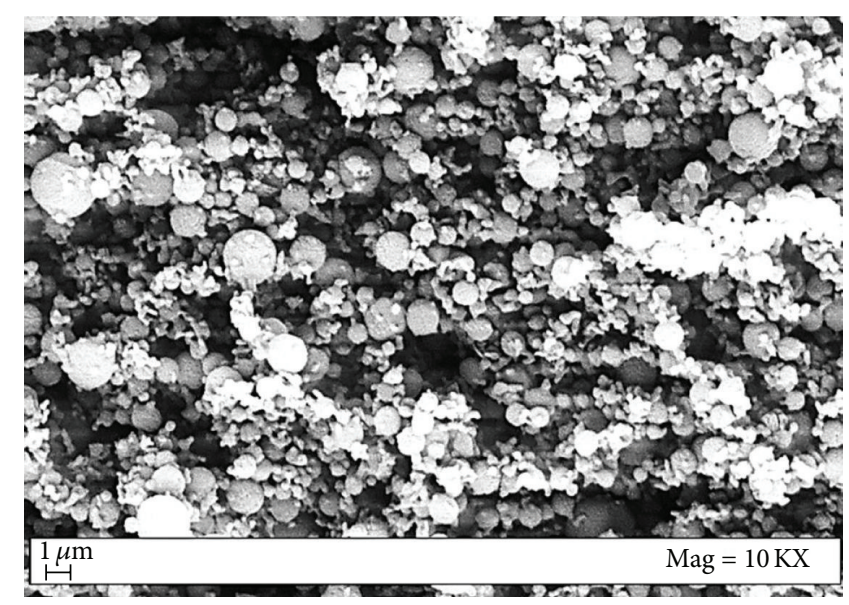

Figure 3: Dexamethasone microparticles obtained by SAA at $40^{\circ} \mathrm{C}$ and 76 bar in the saturator and $70^{\circ} \mathrm{C}$ and 1.6 bar in the precipitator.

show a good solubility in this solvent. Ethanol has also a large affinity with $\mathrm{CO}_{2}$; therefore, a large quantity of $\mathrm{CO}_{2}$ can be dissolved in the ethanolic solution, allowing a large reduction of viscosity. Figure 2 shows the equilibria between ethanol and $\mathrm{CO}_{2}$ and the operative point for SAA micronization experiments.

At the operative conditions used, the complete solubilisation of $\mathrm{CO}_{2}$ in ethanol solution can be expected. Previous work on PVP micronization [24] demonstrated that no precipitation of PVP takes place in the saturator when operated at $40^{\circ} \mathrm{C}, 76$ bar, and GLR $=1.8\left(x_{\mathrm{CO}_{2}}=0.62\right)$.

Dexamethasone was micronized in a previous work [25] but using methanol and acetone as solvents. Therefore, a feasibility test was performed on dexamethasone using ethanol as solvent. Figure 3 shows a photomicrograph of dexamethasone microparticles obtained by SAA at $40^{\circ} \mathrm{C}$ and 76 bar in the saturator and $70^{\circ} \mathrm{C}$ and 1.6 in the precipitator.

Spherical and nonaggregated microparticles of dexamethasone were obtained. Then, the production of composite microparticles was attempted by SAA setting the same operative conditions used in dexamethasone experiments; drug/polymer weight ratios were $1 / 2,1 / 4$ and $1 / 8$. Figure 4 shows photomicrograph of particles obtained at $R=1 / 4$ and $R=1 / 8$. Particles obtained at drug/polymer weight ratio of $1 / 2$ were not proposed since their morphology is identical to the ones reported in Figure 4.

FESEM images, reported in Figure 4, show that spherical particles were obtained at all drug/polymer ratios tested. Figure 5 shows the volumetric cumulative particle size distribution of dexamethasone and dexamethasone-PVP microparticles obtained by SAA.

Dexamethasone microparticles show the larger mean diameter, $1.7( \pm 0.35) \mu \mathrm{m}$, whereas the composite particles have a mean diameter of $0.76( \pm 0.2), 0.8( \pm 0.2)$, and 0.99 $( \pm 0.2) \mu \mathrm{m}$ for $R=1 / 2,1 / 4$, and $1 / 8$, respectively. The overall result is that the presence of PVP reduced particle size and distribution with respect to dexamethasone precipitates alone. Probably the presence of PVP allows a further decrease of viscosity in the starting solution. The reduction of mean size can allow enhancing also the dissolution rate

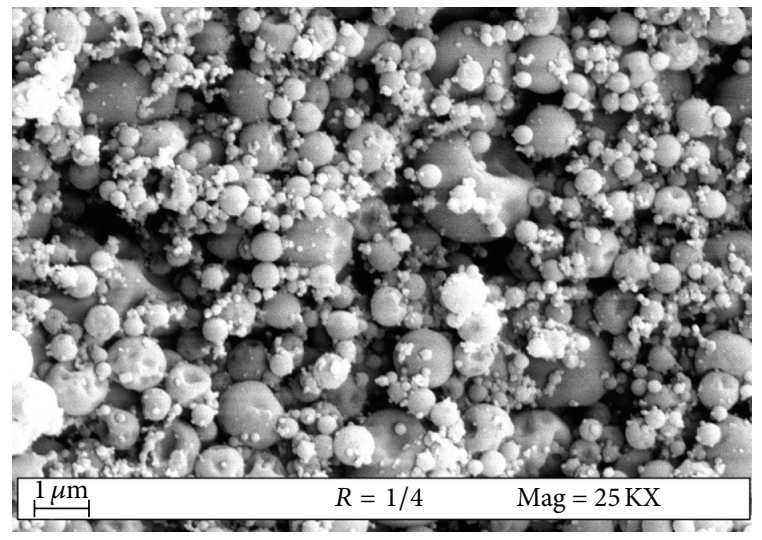

(a)

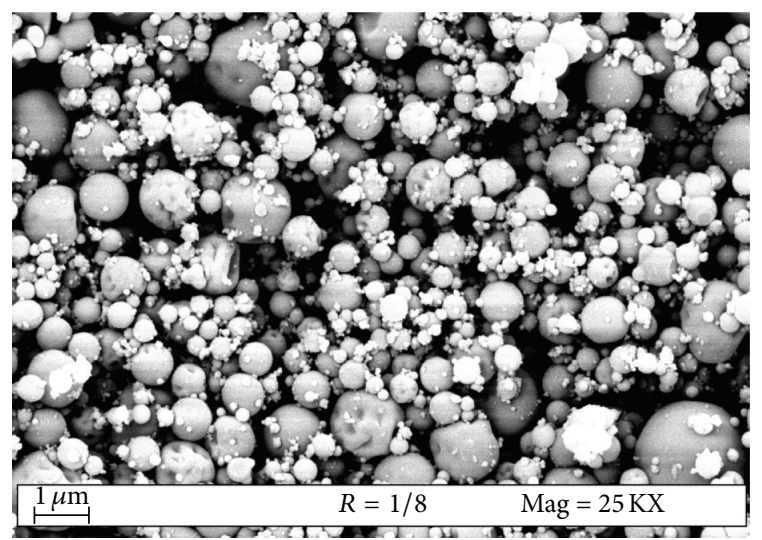

(b)

FIGURE 4: FESEM images of dexamethasone-PVP microparticles, with $R=1 / 4$ and $R=1 / 8$, obtained by SAA operated at $40^{\circ} \mathrm{C}$ and 76 bar in the saturator and $70^{\circ} \mathrm{C}$ and 1.6 bar in the precipitator.

of dexamethasone in water solution. This result is expected for SAA process, since the parameters that have the stronger influence on particle size and distribution are temperatures in the saturator and in the precipitator, concentration of solute 


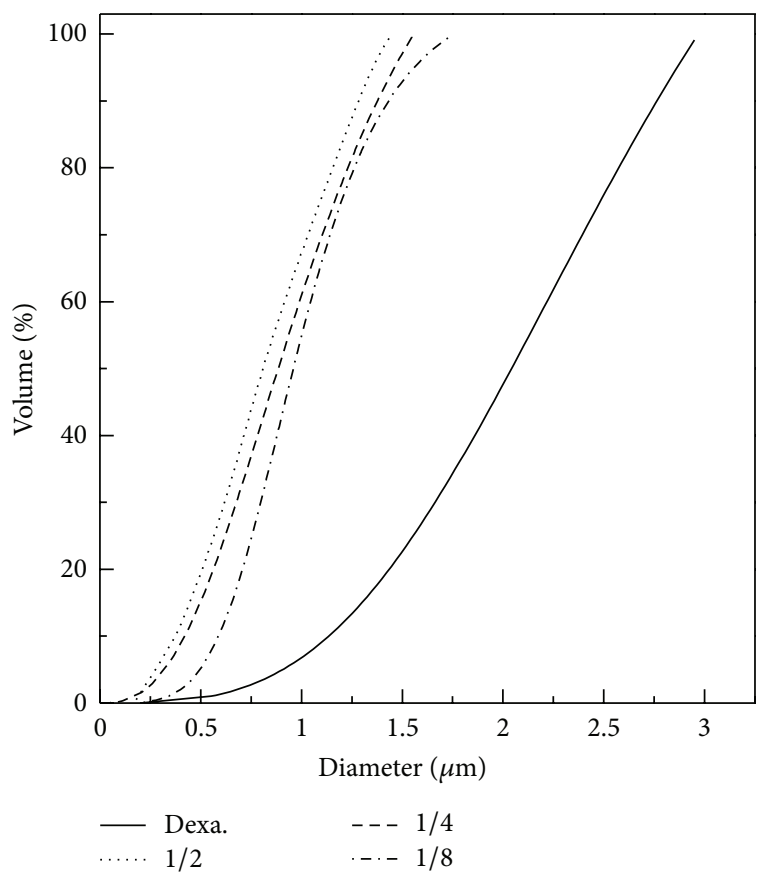

FIgURE 5: Volumetric cumulative particle size distribution of dexamethasone-PVP composite particles produced by SAA at different drug/polymer weight ratios.

and $\mathrm{CO}_{2}$ molar fraction, as explained in previous works $[9,20]$.

3.1. Loading and Encapsulation Efficiency. Loading of dexamethasone in composite microparticles was measured by UV-vis analysis and was of about $95 \%( \pm 5)$ for all the drug/polymer ratios selected.

To test the efficiency of dexamethasone-PVP coprecipitates in improving the dissolution rate of poor soluble drug, dissolution experiments of dexamethasone in water solutions were performed. To verify the improvement in drug dissolution rate of SAA coprecipitates the dissolution rate of composite particles was compared with untreated dexamethasone. Figure 6 shows the corresponding dissolution profiles.

An increase of dissolution rate of dexamethasone was obtained when it was loaded in PVP. The dissolution rate depended on drug/polymer ratio, since when the amount of drug was lower, the dissolution rate increased. This improvement is due to the production of more efficient dispersion of the drug in the polymeric matrix [26].

3.2. Characterization: $X R P D$. The solid state of the untreated dexamethasone was reported also in previous work [25], and the untreated drug is crystalline. Figure 7 shows the XRPD analysis of composite particles produced by SAA.

The characteristic peaks of the crystalline structure of dexamethasone, reported in the graph of Figure $7(10<2 \theta<$ 20 ), are not present in the analysis related to composite particles. Therefore, only amorphous particles were produced by SAA in the case of dexamethasone-PVP coprecipitates. This

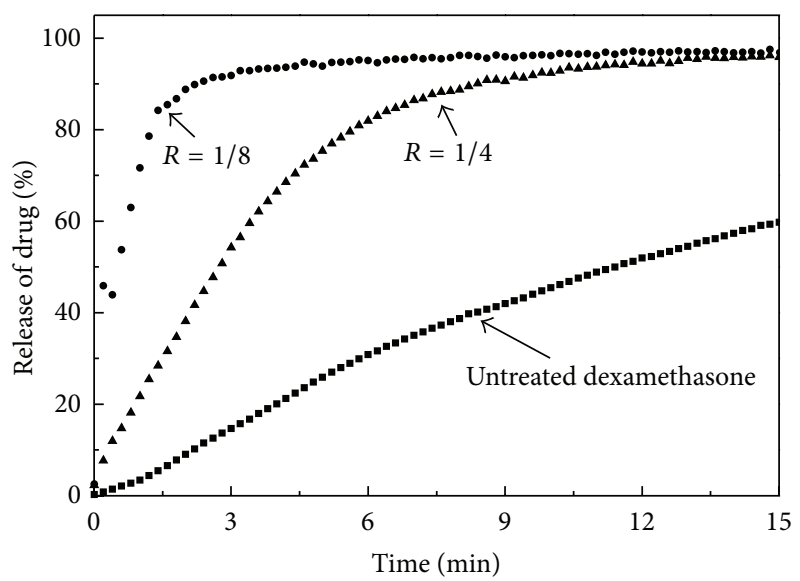

FIGURE 6: Dissolution rate of dexamethasone-PVP composite particles produced by SAA with respect to the untreated drug, in physiological solution.

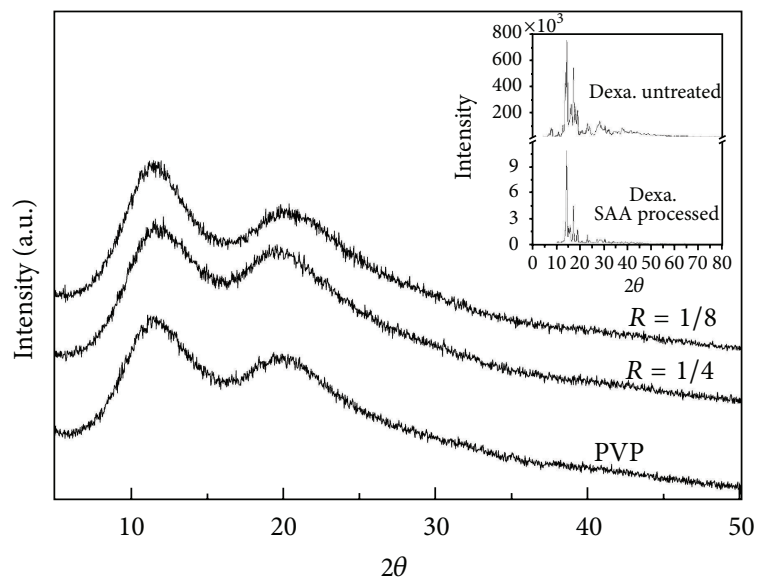

FIGURE 7: XRPD related to the PVP untreated and PVP microparticles produced by SAA using different solvents.

result is not surprising since previous work demonstrated that SAA process allows reducing crystalline degree of several compounds [27]. As a rule, the amorphous particles show a larger dissolution rate if compared with crystalline particles [28].

\section{Conclusion}

SAA process demonstrated to be very efficient in the micronization of drug-PVP composite particles. The amount of PVP in coprecipitates is the key factor in controlling the dissolution rate of dexamethasone. Moreover SAA process induces the formation of disperse and amorphous dexamethasone particles that show a higher dissolution rate in water solutions.

\section{Conflict of Interests}

The authors declare no conflict of interests. 


\section{References}

[1] F. I. Kanaze, E. Kokkalou, I. Niopas, P. Barmpalexis, E. Georgarakis, and D. Bikiaris, "Dissolution rate and stability study of flavanone aglycones, naringenin and hesperetin, by drug delivery systems based on polyvinylpyrrolidone (PVP) nanodispersions," Drug Development and Industrial Pharmacy, vol. 36, no. 3, pp. 292-301, 2010.

[2] K. J. Crowley and G. Zografi, "The effect of low concentrations of molecularly dispersed poly(vinylpyrrolidone) on indomethacin crystallization from the amorphous state," Pharmaceutical Research, vol. 20, no. 9, pp. 1417-1422, 2003.

[3] H. Lee, S. Lee, C. Xu et al., "Synthesis and characterization of PVP-coated large core iron oxide nanoparticles as an MRI contrast agent," Nanotechnology, vol. 19, no. 16, Article ID 165101, 2008.

[4] H. Kamada, Y. Tsutsumi, Y. Yamamoto et al., "Antitumor activity of tumor necrosis factor- $\alpha$ conjugated with polyvinylpyrrolidone on solid tumors in mice," Cancer Research, vol. 60, no. 22, pp. 6416-6420, 2000.

[5] V. Tantishaiyakul, N. Kaewnopparat, and S. Ingkatawornwong, "Properties of solid dispersions of piroxicam in polyvinylpyrrolidone," International Journal of Pharmaceutics, vol. 181, no. 2, pp. 143-151, 1999.

[6] K. E. Wu, J. Li, W. Wang, and D. A. Winstead, "Formation and characterization of solid dispersions of piroxicam and polyvinylpyrrolidone using spray drying and precipitation with compressed antisolvent," Journal of Pharmaceutical Sciences, vol. 98, no. 7, pp. 2422-2431, 2009.

[7] H. H. Y. Tong, Z. Du, G. N. Wang et al., "Spray freeze drying with polyvinylpyrrolidone and sodium caprate for improved dissolution and oral bioavailability of oleanolic acid, a BCS Class IV compound," International Journal of Pharmaceutics, vol. 404, no. 1-2, pp. 148-158, 2011.

[8] G. D. Porta and E. Reverchon, "Nanostructured microspheres produced by supercritical fluid extraction of emulsions," Biotechnology and Bioengineering, vol. 100, no. 5, pp. 1020-1033, 2008.

[9] S. Liparoti, R. Adami, and E. Reverchon, "PEG micronization by supercritical assisted atomization, operated under reduced pressure," Journal of Supercritical Fluids, vol. 72, pp. 46-51, 2012.

[10] H. R. Costantino, L. Firouzabadian, W. Chichih et al., "Protein spray freeze drying. 2. Effect of formulation variables on particle size and stability," Journal of Pharmaceutical Sciences, vol. 91, no. 2, pp. 388-395, 2002.

[11] G. Caputo, R. Adami, and E. Reverchon, "Analysis of dissolvedgas atomization: supercritical $\mathrm{CO}_{2}$ dissolved in water," Industrial and Engineering Chemistry Research, vol. 49, no. 19, pp. 9454-9461, 2010.

[12] E. Reverchon, R. Adami, S. Cardea, and G. D. Porta, "Supercritical fluids processing of polymers for pharmaceutical and medical applications," Journal of Supercritical Fluids, vol. 47, no. 3, pp. 484-492, 2009.

[13] J. Kluge, F. Fusaro, G. Muhrer, R. Thakur, and M. Mazzotti, "Rational design of drug-polymer co-formulations by $\mathrm{CO}_{2}$ antisolvent precipitation," Journal of Supercritical Fluids, vol. 48, no. 2, pp. 176-182, 2009.

[14] I. De Marco and E. Reverchon, "Supercritical carbon dioxide + ethanol mixtures for the antisolvent micronization of hydrosoluble materials," Chemical Engineering Journal, vol. 187, pp. 401409, 2012.
[15] M. V. Sosa, S. Rodríguez-Rojo, F. Mattea, M. Cismondi, and M. J. Cocero, "Green tea encapsulation by means of high pressure antisolvent coprecipitation," Journal of Supercritical Fluids, vol. 56, no. 3, pp. 304-311, 2011.

[16] E. Reverchon and G. Della Porta, “Terbutaline microparticles suitable for aerosol delivery produced by supercritical assisted atomization," International Journal of Pharmaceutics, vol. 258, no. 1-2, pp. 1-9, 2003.

[17] E. Reverchon and G. Della Porta, "Micronization of antibiotics by supercritical assisted atomization," Journal of Supercritical Fluids, vol. 26, no. 3, pp. 243-252, 2003.

[18] Q. Wang, Y. Guan, S. Yao, and Z. Zhu, "Controllable preparation and formation mechanism of BSA microparticles using supercritical assisted atomization with an enhanced mixer," Journal of Supercritical Fluids, vol. 56, no. 1, pp. 97-104, 2011.

[19] R. Adami, L. S. Osséo, and E. Reverchon, "Micronization of lysozyme by supercritical assisted atomization," Biotechnology and Bioengineering, vol. 104, no. 6, pp. 1162-1170, 2009.

[20] R. Adami, S. Liparoti, and E. Reverchon, "A new supercritical assisted atomization configuration, for the micronization of thermolabile compounds," Chemical Engineering Journal, vol. 173, no. 1, pp. 55-61, 2011.

[21] G. D. Porta, R. Adami, P. Del Gaudio, L. Prota, R. Aquino, and E. Reverchon, "Albumin/gentamicin microspheres produced by supercritical assisted atomization: optimization of size, drug loading and release," Journal of Pharmaceutical Sciences, vol. 99, no. 11, pp. 4720-4729, 2010.

[22] Ž. Knez, M. Škerget, L. Ilič, and C. Lütge, "Vapor-liquid equilibrium of binary $\mathrm{CO}_{2}$-organic solvent systems (ethanol, tetrahydrofuran, ortho-xylene, meta-xylene, para-xylene)," Journal of Supercritical Fluids, vol. 43, no. 3, pp. 383-389, 2008.

[23] E. Reverchon, "Supercritical-assisted atomization to produce micro- and/or nanoparticles of controlled size and distribution," Industrial and Engineering Chemistry Research, vol. 41, no. 10, pp. 2405-2411, 2002.

[24] S. Liparoti, Production of micro and nanoparticles of thermolabile compounds using supercritical assisted atomization [Ph.D. doctoral thesis], Department of Industrial Engineering, University of Salerno, 2012.

[25] G. Della Porta, S. F. Ercolino, L. Parente, and E. Reverchon, "Corticosteroid microparticles produced by supercriticalassisted atomization: process optimization, product characterization, and "in vitro" performance," Journal of Pharmaceutical Sciences, vol. 95, no. 9, pp. 2062-2076, 2006.

[26] E. Reverchon and A. Antonacci, "Chitosan microparticles production by supercritical fluid processing," Industrial and Engineering Chemistry Research, vol. 45, no. 16, pp. 5722-5728, 2006.

[27] L. Martin, S. Liparoti, G. D. Porta et al., "Rotenone coprecipitation with Biodegradable polymers by Supercritical Assisted Atomization," The Journal of Supercritical Fluids, 2013.

[28] G. C. Bazzo, D. B. Caetano, M. L. T. Boch et al., "Enhancement of felodipine dissolution rate through its incorporation into eudragit ${ }^{\circledR}$ E-PHB polymeric microparticles: in vitro characterization and investigation of absorption in rats," Journal of Pharmaceutical Sciences, vol. 101, no. 4, pp. 1518-1523, 2012. 

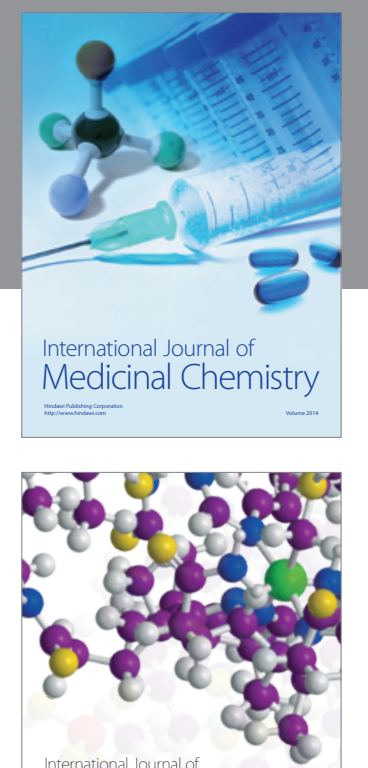

\section{Carbohydrate} Chemistry

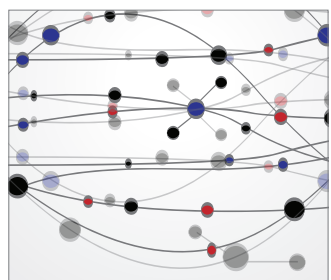

The Scientific World Journal
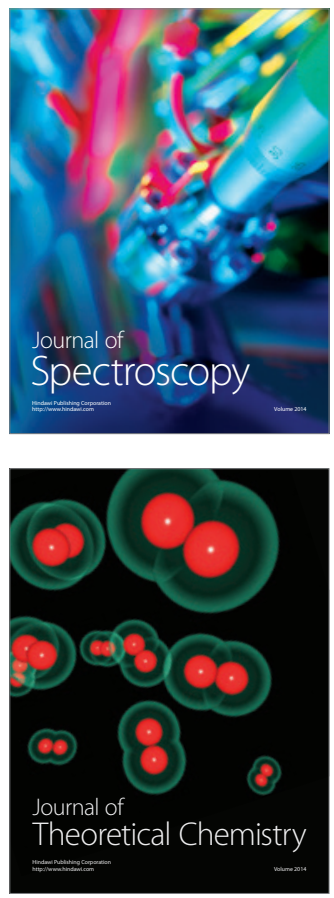
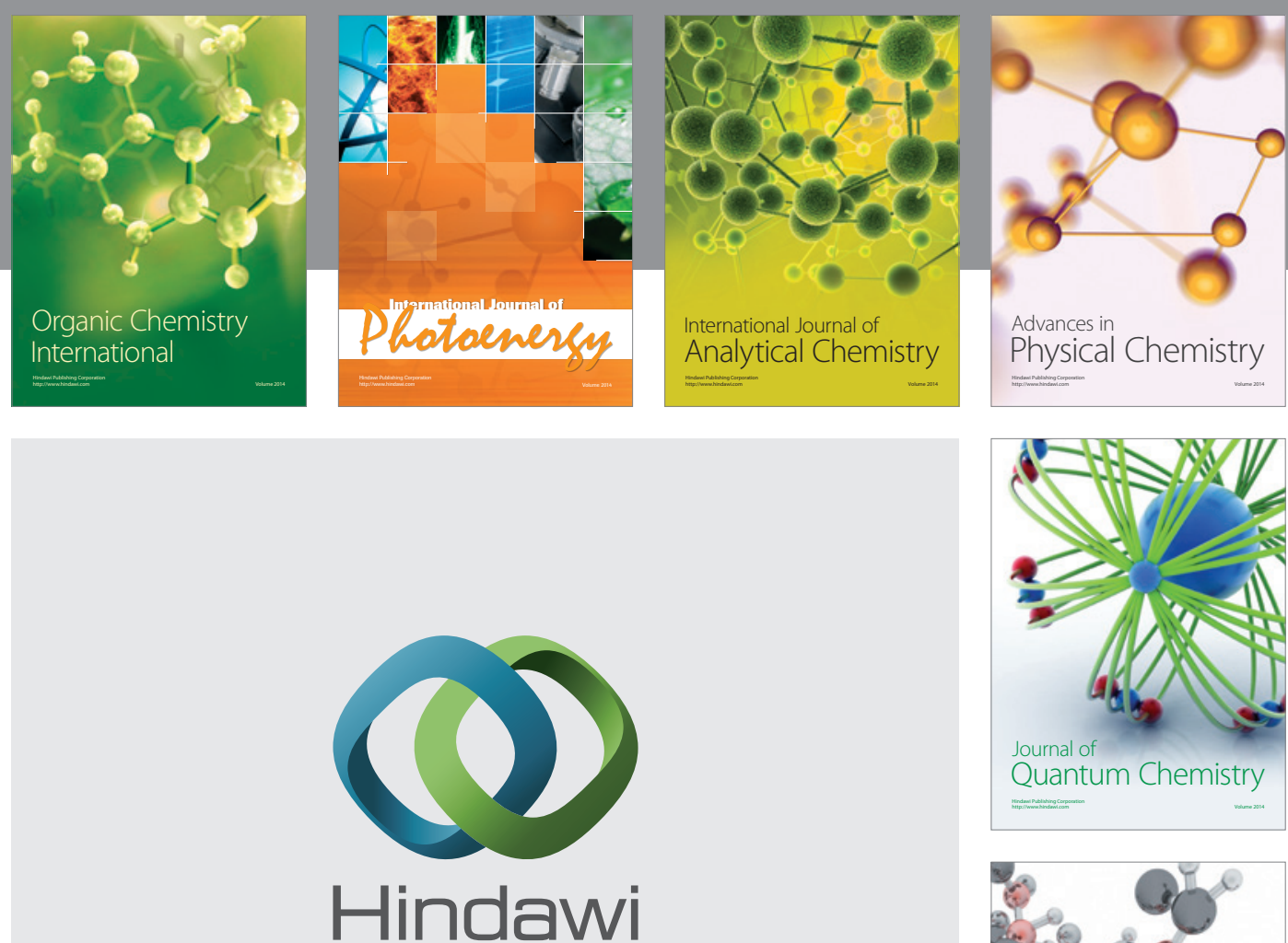

Submit your manuscripts at

http://www.hindawi.com

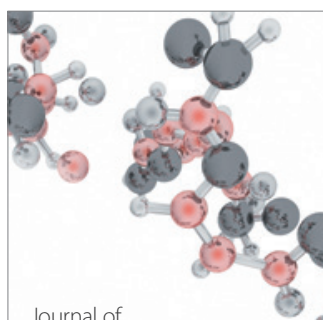

Analytical Methods

in Chemistry

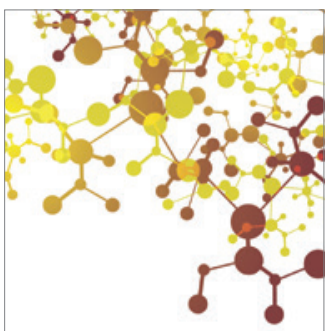

Journal of

Applied Chemistry

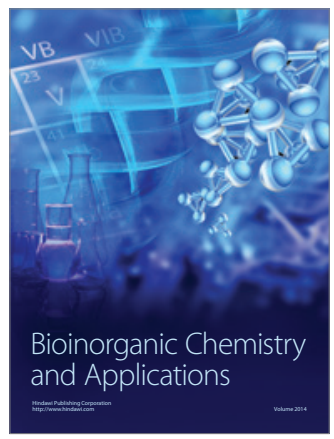

Inorganic Chemistry
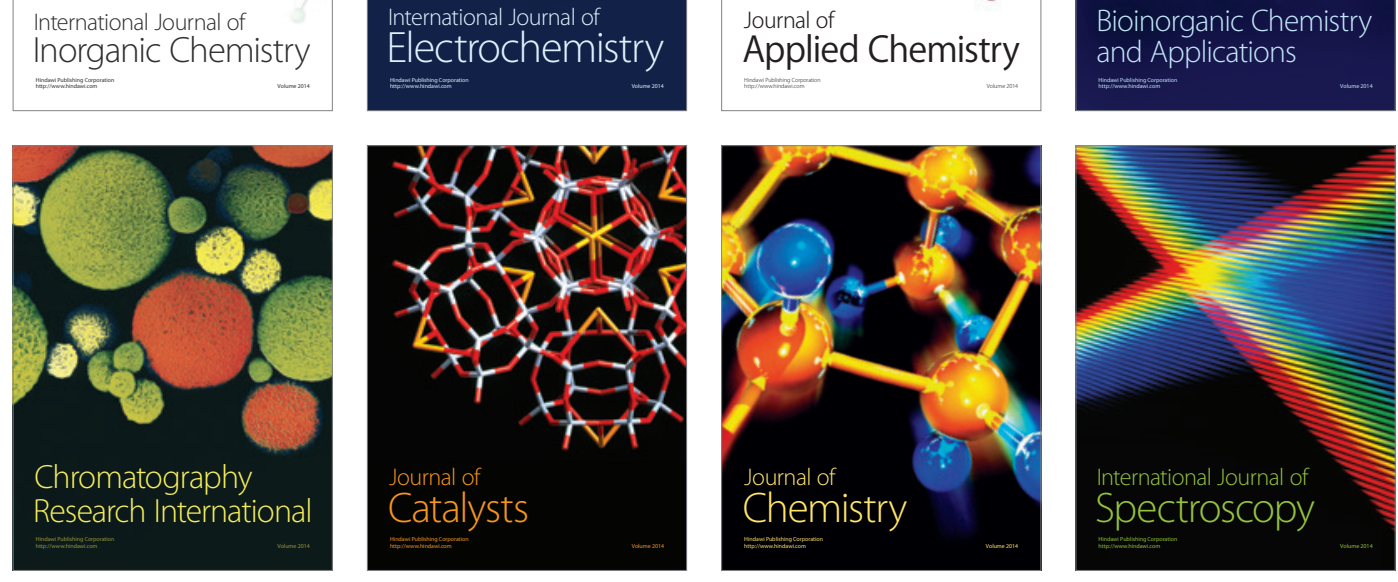